\title{
LETRAMENTO CRÍTICO E O ENSINO DE LÍNGUA PORTUGUESA: ANÁLISE DE UM LIVRO DIDÁTICO
}

\section{Tainá Almeida*}

RESUMO: O presente artigo tem como objetivo apresentar os resultados da análise de um livro didático de língua portuguesa realizada à luz das contribuições teóricas dos estudos do Letramento Crítico, decorrentes da Pedagogia Freireana. O livro analisado é o Português Linguagens $9^{\circ}$ ano de William Cereja e Thereza Cochar. Interessou-nos avaliar se as unidades temáticas são construídas a partir de uma abordagem crítica, se contemplam gêneros textuais que refletem as práticas de letramento contemporâneas e se as atividades de leitura propostas são condizentes com a realidade social do seu público-alvo. Os resultados dessa investigação qualitativa de análise documental demonstraram que o livro didático em questão possui potencialidades de colaboração para a formação de um leitor crítico e socialmente engajado.

PALAVRAS-CHAVE: Ensino Crítico de Língua Portuguesa; Letramento Crítico; Pedagogia Freiriana.

\section{Introdução}

Ensinar língua não é uma tarefa simples, especialmente quando a compreensão que se tem dela vai muito além de um conjunto de símbolos, grafemas e fonemas que representam a realidade. A língua é prática social e, como tal, está inserida na história, na cultura e nos discursos de uma determinada sociedade, sendo tanto veículo de ideologias como instrumento de transformação social.

Por isso, a concepção de língua como prática social essencialmente política e ideológica vem sendo cada vez mais aceita no grande arcabouço dos estudos linguísticos. Bakhtin/Voloshinov (2002), ainda no início do século XX quando da publicação de Marxismo e Filosofia da linguagem, e Rajagopalan (2003), nos dias atuais, advoga(ra)m a favor dessa compreensão linguística cujos reflexos devem ser sentidos na maneira como ensinamos língua em nossas salas de aula.

\footnotetext{
* Doutoranda em Língua e Cultura pela Universidade Federal da Bahia (Ufba). Mestre em Letras: Cultura, Educação e Linguagens pela Universidade Estadual do Sudoeste da Bahia (Uesb).
} 
Enxergar a língua como prática social que tanto reflete quanto constrói os discursos que permeiam a sociedade requer do professor a consciência de que o ensino de língua não deve se dar de forma alienada e descontextualizada, alheio às demandas sociais, à luta de classes, às relações de poder e aos problemas vivenciados pelo seu alunado.

É nessa cadeia de pensamento que surge o Letramento Crítico, área de estudos que reivindica a necessidade de engajamento do aluno como sujeito social e crítico em suas práticas de leitura. Por essa ótica - que também dialoga com a perspectiva freireana, por que lhe é decorrente -, não é possível ensinar língua portuguesa sem ensinar o sujeito a existir no mundo, a se compreender como um sujeito social e, por isso, um agente de mudança da sociedade.

O letramento crítico não tem a intenção de criar uma metodologia fixa, por meio da qual o professor teria êxito se a cumprisse. Mostra-se, na verdade, como uma atitude assumida em diferentes contextos, nos quais o professor deve incentivar posturas combativas e de curiosidade crítica nas práticas letradas dos seus alunos. E mais, o letramento crítico busca a irresignação do professor, que não se conforma com as disparidades contidas no seio da sociedade, mas busca, através do seu múnus, despertar a consciência crítica dos seus alunos.

A partir dessas constatações, nos indagamos acerca do papel perpetrado pelo livro didático nas práticas de leitura dos alunos e como ele pode contribuir (ou não) para que o professor desenvolva uma práxis crítica em suas aulas de língua portuguesa. Assim, procuramos, por meio da elaboração deste artigo, responder à seguinte pergunta: À luz dos estudos do Letramento Crítico e da Pedagogia Freireana, o livro didático Português Linguagens $9^{\circ}$ ano apresenta potencialidades de contribuição para a formação de leitores críticos e socialmente engajados? A fim de respondê-la, nos utilizamos das discussões teóricas propostas por Paulo Freire (1987, 1996), João Wanderley Geraldi (1984), Roxane Rojo (2009, 2010) e Walkyria Monte Mor (2007), para citar alguns, e da análise desse livro didático de língua portuguesa elaborado para o $9^{\circ}$ ano do Ensino Fundamental. Desse modo, não só discutimos acerca da contribuição dessas áreas do conhecimento para a formação cidadã 
do aluno, mas também analisamos se o material didático escolhido aborda temas críticos e socialmente sensíveis que contribuam para a formação integral do indivíduo.

Este artigo se encontra dividido em quatro seções: a Introdução; a seção que discute as principais contribuições da Pedagogia Freireana e dos Estudos do Letramento para o ensino crítico de línguas; a seção de análise do livro didático escolhido e, por fim, as nossas Considerações Finais.

\section{Letramento crítico e a pedagogia freireana: caminhos para o ensino crítico de} língua portuguesa

O conceito de Letramento se desenvolveu fundamentado na concepção de língua como prática social. O termo começou a ser utilizado no Brasil a partir da década de 90 (KLEIMAN, 2008), mas seu conceito está presente em estudos de quase três décadas antes, época em que Paulo Freire, grande pedagogo pernambucano, já influenciava gerações (inter)nacionalmente com suas obras acerca da alfabetização conscientizadora. Dessa forma, o conceito de Letramento é o mesmo presente na alfabetização freireana e está relacionado às diversas práticas de uso social da escrita, as quais são situadas, ou seja, acontecem em um dado momento, dentro de um contexto histórico e social específico e por agentes sociais particulares.

O vocábulo Letramento advém da tradução da palavra inglesa literacy que pode ser traduzida por alfabetização ou letramento, a depender do contexto. Nos países de língua inglesa, o rompimento com a visão estruturalista da língua e o surgimento da nova compreensão de língua como prática social originou os chamados New Studies of Literacy, que em português quer dizer Novos Estudos do Letramento, cuja novidade reside na transição conceitual de literacy (traduzida e entendida como mera alfabetização, ou seja, aprendizagem dos códigos da escrita e leitura de palavras) para os new studies of literacy (que comportam o ensino de língua visto pela sua perspectiva social e todas as implicações por ela geradas).

No Brasil, no entanto, o termo Letramento começou a ser utilizado já incorporando o aspecto social da língua e, por isso, Kleiman (2008) acredita que não há necessidade do uso do termo Novos Estudos do Letramento no Brasil, uma vez que aqui todos os estudos que 
decorrem do conceito de Letramento são novos. Portanto, para nós brasileiros, o termo alfabetização representa apenas uma das práticas sociais de escrita - aquela realizada na e pela escola - e, por isso, ela não pode ser confundida com Letramento, nem os termos serem usados como sinônimos, uma vez que a alfabetização faz parte do Letramento que, por ser um conceito mais amplo, engloba todas as atividades da vida em que a escrita esteja presente.

$\mathrm{Na}$ prática, inserir o Letramento nas aulas de língua portuguesa requer do professor consciência sobre a dimensão social da língua, reconhecimento de que ela não é neutra e que tampouco o pode ser o seu ensino, pois, como esclareceu Bakhtin (2002, p. 95), "não são palavras o que pronunciamos ou escutamos, mas verdades ou mentiras, coisas boas ou más, importantes ou triviais, agradáveis ou desagradáveis etc. A palavra está sempre carregada de um conteúdo ou de um sentido ideológico ou vivencial.”. Ou seja, ensinar uma língua não se restringe à explanação de seus aspectos estruturais, mas abarca discussões acerca da ampla rede de significados tecidas a partir de seu uso, que é sempre contextual e ideológico.

A fim de compreender o nascedouro do conceito de Letramento, nos debruçaremos por um momento na Pedagogia Freireana e no seu legado para a educação linguística.

\subsection{Paulo Freire e seu legado crítico para a educação linguística}

Paulo Freire, já na década de 60, demonstrava sua compreensão acerca da língua como prática social quando começou a desenvolver sua alfabetização de adultos. Para ele, a leitura de mundo antecede a leitura da palavra, e não só a antecede como lhe concede sentido e pertinência. A leitura da palavra não é algo que pode ser superposto ao educando, deve ser algo construído com ele, conferindo-lhe um saber linguístico estrutural a partir do saber de mundo, cultural já previamente vivenciado por ele.

É aos seus pais que Freire confere a responsabilidade pela sua visão acerca do ensino, pois teria ele mesmo aprendido a ler debaixo da mangueira do quintal de sua casa, tendo os pais como professores, o chão de terra como quadro-negro e gravetos como giz. 
Tendo vivido essa primeira experiência com as letras escritas de forma tão íntima e entrelaçada com sua realidade infantil, Freire não teve dificuldades ao chegar à escola e ter seus estudos continuados pela condução de sua saudosa professora Eunice Vasconcelos, profissional que compreendia a imprescindível conexão entre a leitura de mundo e a leitura da palavra, ou a leitura da "palavramundo", como Freire gostava de falar (FREIRE, 1989).

Com 21 (vinte e um) anos, formado em Direito pela Faculdade de Direito do Recife, casado e com 5 (cinco) filhos, Freire passa a ser professor de língua portuguesa no colégio onde se formou. Essa vivência em sala de aula definiria a sua atuação profissional pelo resto da vida. Deixando a carreira de advogado logo no primeiro caso em que atuou, Freire se dedica à educação com o esforço e paixão característicos dos vocacionados. 3 (três) anos mais tarde, já era diretor do Departamento de Educação e Cultura de Pernambuco e, um ano depois, assume a direção do Setor de Educação do SESI (Serviço Social da Indústria) de Recife. É no SESI onde Freire tem seu primeiro contato com a educação de trabalhadores e desenvolve o que mais tarde seria conhecido como "Método Paulo Freire".

Foi a experiência de alfabetização de 300 (trezentos) adultos realizada em Angicos, no Rio Grande do Norte, num curto período de 40 (quarenta) dias que chamou a atenção do governo brasileiro. A aplicação do seu original método de alfabetização envolvia os seguintes passos: a) integração dos alfabetizadores com o público-alvo; b) audição de seus problemas sociais; c) coleta do vocabulário básico da região a fim de ensinar a partir do que já era de conhecimento dos alunos; d) realização de "Círculos de Cultura", que eram reuniões com os trabalhadores para discutir a vida, o valor do trabalho que exerciam, o conceito de cultura e, daí, desenvolver consciência crítica sobre seu papel e importância sociais; e) ensino das letras e palavras a partir dos temas geradores extraídos das falas dos alunos. O objetivo desse trabalho desenvolvido sob a liderança de Freire era o de alfabetizar os camponeses e politizá-los.

Por causa do momento histórico em que iniciou seu projeto de alfabetização crítica, ou conscientizadora, o período do Regime Militar, Freire foi exilado no Chile, continuando e expandindo seu trabalho e desenvolvimento teórico lá, bem como em todas as demais nações pelas quais passou. Após 16 (dezesseis) anos de exílio, Freire retorna ao Brasil já 
profundamente respeitado internacionalmente. Seus livros foram publicados em diversas línguas e seu conceito de educação encontra abrigo em muitas partes do mundo. Foram 35 (trinta e cinco) livros publicados no total, dentre eles, os célebres Pedagogia do oprimido e Pedagogia da autonomia.

Em suma, a pedagogia de Freire se ancora em alguns princípios, dentre eles, a profunda relação entre educação e a situação social do indivíduo; aprender a ler e a escrever não pode ser um processo mecânico e com fins mecanicistas, mas deve ensinar o aprendiz a ler o mundo e não somente as palavras, a fim de que esteja apto a agir no mundo por meio delas; o ensino só faz sentido quando é algo construído com o aluno e não entregue a ele como algo pronto. Freire teceu duras críticas à educação convencional, a que ele chamou de "bancária", propondo em oposição a ela uma educação libertadora. Sua pedagogia era voltada para a libertação tanto dos oprimidos - cidadãos pertencentes às classes baixas, trabalhadoras, sem instrução formal - quanto dos opressores - aqueles que compunham a classe economicamente dominante. Sua atuação pedagógica era em favor da diminuição da desigualdade social, em prol da democracia e da participação popular. Para ele, educação sem leitura social está fadada ao fracasso (FREIRE, 1987, 1996). Os fundamentos teóricos e práticos de sua atuação na educação de jovens e adultos encontra(ra)m ressonância em todos os estudos linguísticos críticos realizados desde então, sobretudo aqueles do Letramento.

Por esta razão, feitas as considerações acerca dos princípios orientadores da pedagogia de Freire, nos voltaremos para os estudos do Letramento Crítico realizados no Brasil e sua importância para a efetivação de um ensino contextualizado e significativo da língua portuguesa.

\subsection{Letramento crítico no Brasil: por um ensino significativo de língua portuguesa}

No tópico anterior, pudemos perceber o quão transgressoras foram as ideias de Paulo Freire, que se posicionava ferozmente contra o ensino convencional, propondo práticas que pudessem não só letrar, como emancipar o indivíduo. Por isso, podemos afirmar 
que no Brasil, do ponto de vista histórico, Paulo Freire, mesmo sem utilizar a expressão letramento crítico, ao tratar a língua como prática social, foi o precursor desse movimento. Assim, o Letramento Crítico pode ser entendido como o ensino da língua, seja ela materna ou estrangeira, que ultrapassa o aprendizado das regras e códigos linguísticos, conduzindo o aluno a entender e a discutir o contexto social, político e ideológico no qual está inserido. A língua é vista, portanto, como prática social. Logo, o Letramento Crítico tem

uma concepção fundamentalmente diferente em relação à leitura. Essencialmente, os alunos do letramento crítico abordam o processo de significação textual como um processo de construção, e não de extração; nós atribuímos sentidos a um texto ao invés de extrairmos os significados dele. Acima de tudo, o significado textual é compreendido num contexto sócio-histórico e de relações de poder, não somente como o produto ou a intenção de um autor. Além disso, a leitura é um ato de conhecer o mundo (além das palavras do texto) e uma forma de transformação social. (CERVET'TI et. al. apud JORDÃO; FOGAÇA, 2007, p. 91)

Apontadas tais premissas conceituais sobre o Letramento Crítico, podemos destacar ainda outro fator relevante para a formação do leitor crítico no cenário atual: as mudanças que a contemporaneidade apresenta no que diz respeito ao acesso à informação e à produção do conhecimento. A escola, que antes era tida como o único local detentor de "verdades", agora se vê diante de uma sociedade onde o conhecimento está em todo e qualquer lugar, a dita “aprendizagem ubíqua”. Daí a importância do trabalho escolar condizer com as novas práticas de letramento que surgem na sociedade e conduzir um ensino de línguas que se adeque às novas realidades que surgem em tempo recorde. Nesse sentido, Monte Mor (2014, p. 35) afirma:

Essa premissa permite a interpretação de que a escola não mais representa o único local privilegiado de aprendizagem para o aluno. Deduz-se que, durante longo tempo, as propostas educacionais priorizaram o modelo, o singular e a homogeneidade, sendo muito recente a abertura para a diversidade, a heterogeneidade e as formas plurais de conhecimento.

Dentro dos estudos do Letramento no Brasil, destacam-se os trabalhos de João Wanderley Geraldi, professor que tem influenciado gerações de docentes e discentes, além 
de participar ativamente em órgãos oficiais de educação. Em 1984, Geraldi foi organizador e autor do livro $O$ texto na sala de aula, que contou com textos de mais outros sete autores. O referido livro propunha uma ressignificação do ensino de Língua Portuguesa, em que o ensino desta disciplina fosse pautado nas práticas e não nos conteúdos, defendendo um ensino baseado na linguística da enunciação e na leitura e produção dos gêneros textuais. Geraldi (1984, p. 56) concebe "[...] a linguagem como o lugar de constituição de relações sociais, onde os falantes se tornam sujeitos". A visão trazida pelo referido livro serviu de base para vários documentos produzidos no Brasil que versam sobre o ensino de língua portuguesa e incorporaram as práticas do Letramento nas suas disposições.

Assim, os documentos oficiais norteadores do ensino de língua portuguesa no Brasil já trazem a visão do Letramento em suas orientações pedagógicas, mas ainda é possível observar que os docentes enfrentam dificuldades, sejam de ordem formativa ou estrutural, para pô-las em prática. Pensando em ajudar os professores nesse processo, o Ministério da Educação lançou em 2005 o Preciso "ensinar" o letramento? Não basta ensinar a ler e a escrever?, escrito por Ângela Kleiman, em que ela esclarece as dúvidas mais comuns dos professores acerca do que (não) é o Letramento e como ele pode auxiliar os docentes na árdua e prazerosa tarefa de formar leitores críticos.

Dessa forma, podemos afirmar que as escolas têm um papel decisivo na formação de agentes sociais cientes da sua responsabilidade com a realidade que os cerca. Como já mencionado anteriormente, todo texto possui uma carga ideológica que "passeia" por sua estrutura, e tal fato não pode passar despercebido pelos alunos, que deverão ter um docente consciente e preparado para mediar a apreensão crítica da leitura. Nesse mesma cadeia de pensamento, Rojo (2009, p. 114) enfatiza que

[...] são cruciais os letramentos críticos que tratam os textos/enunciados como materialidades de discursos, carregados de apreciações e valores, que buscam efeitos de sentido e ecos e ressonâncias ideológicas. É preciso, portanto, um reenfocar do texto, fora da escola, mas principalmente nela, por sua vocação cosmopolita, por sua capacidade de agenciamento de populações locais na direção do universal, dos patrimônios da humanidade. 
Para essa formação crítica dos alunos, é imprescindível a coexistência harmoniosa entre as variadas formas de letramento. Os ditos letramentos institucionalizados são supervalorizados pelas unidades escolares, em detrimento do letramento cultural, o que acaba distanciando o aluno de vivências culturais locais. Nesse sentido, temos "a multiplicidade de práticas de letramento que circulam em diferentes esferas da sociedade e a multiculturalidade, isto é, o fato de que diferentes culturas locais vivem essas práticas de maneira diferente" (ROJO, 2009, p. 109). Assim, o letramento não pode estar adstrito a ensinar o aluno a conhecer apenas os códigos linguísticos, ele precisa entender a realidade social e cultural que o cerca, para que possa discutir e participar dos processos de mudança na sociedade.

Quando pensamos no contato que o aluno estabelece com a escrita desde a infância, percebemos que o livro didático é, para a população brasileira em fase escolar, um dos principais meios de contato com a escrita em sua variante formal ou padrão. Dada a importância do livro didático no processo de letramento formal de uma enorme parcela da população, a sua construção deve estar atenta às demandas da sociedade que, na contemporaneidade, se distancia da mera qualificação para o mercado de trabalho, passando para a construção de um cidadão socialmente responsável. Percebendo o papel de destaque do livro didático, Rojo (2010, p. 438) afirma que

[as] pesquisas sobre letramentos no Brasil têm apontado um lugar de destaque para a escola e o livro escolar na constituição e distribuição dos letramentos. O Indicador Nacional de Alfabetismo Funcional (INAF) aponta a leitura de livros religiosos e escolares como práticas bastante difundidas de letramento no Brasil.

Por isso, os materiais didáticos escolhidos devem refletir essa mesma compreensão de língua e propor textos e atividades que suscitem o diálogo, promovam o debate e incitem à criticidade. Nessa perspectiva, Rojo (2010, p. 443) defende que "[a]s coletâneas dos LDP [Livros Didáticos de Português] não se atenham mais exclusivamente a textos da esfera literária e que possibilitem práticas de letramento de esferas diversificadas de circulação dos discursos, por meio da leitura de textos em gêneros também variados.".

Assim, é necessário mudar a abordagem dos livros didáticos, o que implica superação do modelo tradicional de ensino da língua e de literatura. Durante muito tempo (e ainda 
hoje), o ensino de língua e de literatura foi segmentado, tratado pelas instituições escolares separadamente e, por vezes, por iniciativa de algum professor, acabavam se aproximando. Alcançar um letramento crítico é também entrelaçar os estudos de língua e literatura. $\mathrm{Na}$ mesma linha de raciocínio, Geraldi (1995, p. 58) afirma que “[...] os professores de comunicação e expressão, inconformados com o bizantinismo dos programas oficiais, tem frequentemente tentado superar, na prática, a dicotomia língua/literatura.”.

As questões aqui discutidas demonstram a urgência em adequar os livros didáticos às novas formas de letramento exigidas pela contemporaneidade, introduzindo novos gêneros textuais e novas práticas de leitura que atendam de forma heterogênea os diversos públicos que são submetidos às leituras do livro didático. Devido a essa importância, passaremos à análise do livro didático escolhido.

\section{A formação do leitor crítico: um livro didático em análise}

Neste tópico, nos dedicamos a analisar o livro didático publicado pela Editora Saraiva intitulado Português Linguagens $9^{\circ}$ ano, dos autores William Cereja e Thereza Cochar, à luz dos estudos desenvolvidos pelo Letramento Crítico a fim de verificar se o material pode contribuir para a formação de leitores críticos e socialmente engajados. Dividido em 4 (quatro) unidades, cada uma contendo 3 (três) capítulos, o livro do aluno contém 272 (duzentas e setenta e duas) páginas e o do professor 320 (trezentas e vinte), visto que este último vem acrescido do Manual do Professor em suas páginas finais.

A análise aqui realizada diz respeito às 2 (duas) primeiras unidades do livro em questão e traz informações adicionais advindas do seu texto de apresentação e do Manual do Professor. Acreditamos que os conteúdos selecionados para análise são suficientes para responder ao nosso questionamento motivador, bem como pode auxiliar um provável professor leitor na tarefa de fazer um uso crítico do material didático que tem em mãos.

Logo na apresentação do livro, os autores estipulam seu público-alvo: um aluno curioso, criativo, que sabe opinar, conectado com o mundo por meio das mídias sociais, competente usuário da língua portuguesa nos mais diversos contextos e ávido por aprender mais sobre e por meio (d)ela. Os temas escolhidos para as unidades e capítulos do livro 
refletem o desejo dos autores em provocar o interesse desse tipo de aluno do século XXI e seguem as propostas de temas transversais dos Parâmetros Curriculares Nacionais (PCN).

As unidades se iniciam com a seção Fique ligado! Pesquise! que traz sugestões de livros, filmes, músicas, museus e sites que guardem relação com o que será trabalhado e terminam com duas seções: a Passando a limpo, que é uma atividade de revisão dos conteúdos, e a Intervalo, que propõe a realização de um projeto pelos alunos. Já os capítulos se subdividem em seções chamadas Estudo do texto, Produção de Texto, Para escrever com adequação/coerência/coesão/expressividade, A lingua em foco e Divirta-se. O livro é rico em multiplicidade de gêneros textuais e se preocupa com as demandas sociais do seu público-alvo, como é possível verificar pela escolha dos temas transversais das 4 (quatro) unidades: as redes sociais; a descoberta do amor; os desafios da juventude e contemporaneidade.

Com um total de 55 (cinquenta e cinco) páginas, a Unidade 1 se intitula Caia na rede! e aborda temas de interesse da juventude nos 3 (três) capítulos que a compõem, cujos títulos são, respectivamente, O registro de mim mesmo, Posto... Logo, existo! e Eu: entre o real e o ideal. Nessa unidade, os textos se apresentam com linguagem verbal e não verbal versando sobre o uso das tecnologias e as vantagens e desvantagens a ela atreladas, como o modismo das selfies, o uso das redes sociais, os perigos da internet e o cyberbullying; e sobre os valores do nosso tempo: os valores socialmente apreciados, beleza interior e exterior, tradicionalismo, convenções sociais, o valor da opinião do outro sobre a nossa etc.

A partir da análise dos textos e atividades dessa unidade, percebemos que os autores enxergam o aluno-alvo como um ser social e se basearam nos preceitos do Letramento Crítico para a produção desse volume. Os conteúdos gramaticais são precedidos pela leitura e discussão de textos de variados gêneros que tratam sobre temáticas do universo do seu público-alvo e conduzem à exposição da leitura de mundo do aluno antes da leitura da palavra. As atividades e sugestões de pesquisa, em sua maioria, conferem ao aluno autonomia na construção do seu aprendizado e levam-no à reflexão crítica acerca da sua realidade. No entanto, há uma predominância de atividades interpretativas e gramaticais escritas ao longo dos capítulos, o que pode tornar a sua realização um tanto enfadonha para o adoles- 
cente. É imprescindível, daí, a sensibilidade do professor e adequação do material em benefício do aluno, sempre que julgar pertinente. Assim, no que diz respeito aos princípios da pedagogia freireana, acreditamos que o volume apresenta preocupação com a curiosidade epistemológica, a autonomia, o conhecimento prévio de mundo, a criticidade e a reflexão social do estudante. As imagens abaixo, extraídas do capítulo 3 do livro, exemplificam o que foi dito acerca da escolha dos temas e sua relação com o universo do públicoalvo:

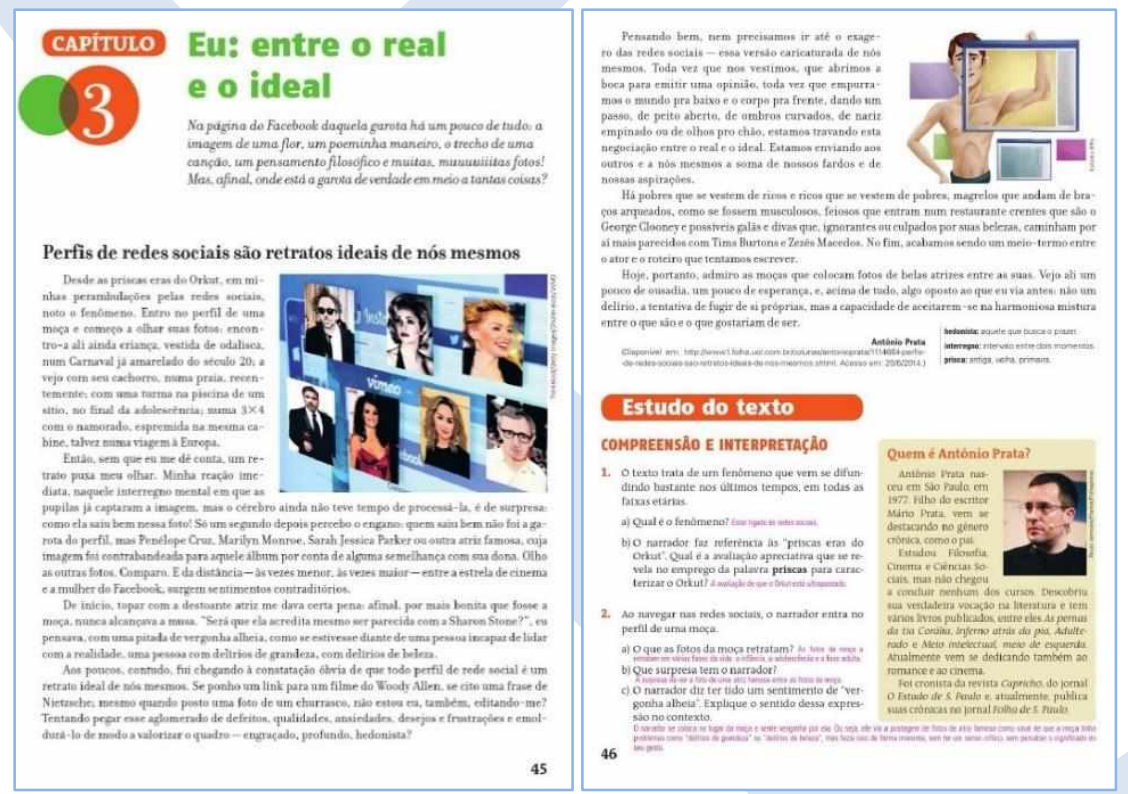

Fonte: Livro didático Português: Linguagens $9^{\circ}$ ano

A Unidade 2 recebe o título de Amor e trata de assuntos que fazem parte da vivência dos adolescentes. Os 3 (três) capítulos que a compõem possuem os seguintes títulos: $O$ primeiro amor, Amar não tem idade e $O$ verdadeiro presente. Assim como na Unidade 1, os textos se apresentam com linguagem verbal e não verbal e tratam do primeiro amor na vida dos adolescentes, que não necessariamente é a paixão dos enamorados, ou mesmo o amor que sentimos pelos amigos e familiares, mas abrange o amor pelas novas descobertas e por determinados objetos. Aborda também se existem limites para o amor, questionando sobre 
o que une duas pessoas, se existe uma idade para amar, possibilitando variadas discussões com os alunos, com a clara intenção de ampliar o espectro do verbo amar. Por fim, trata das várias formas de amor que são desenvolvidas ao longo da vida. O primeiro texto apresentado nesta unidade pode ser visto nas imagens abaixo:

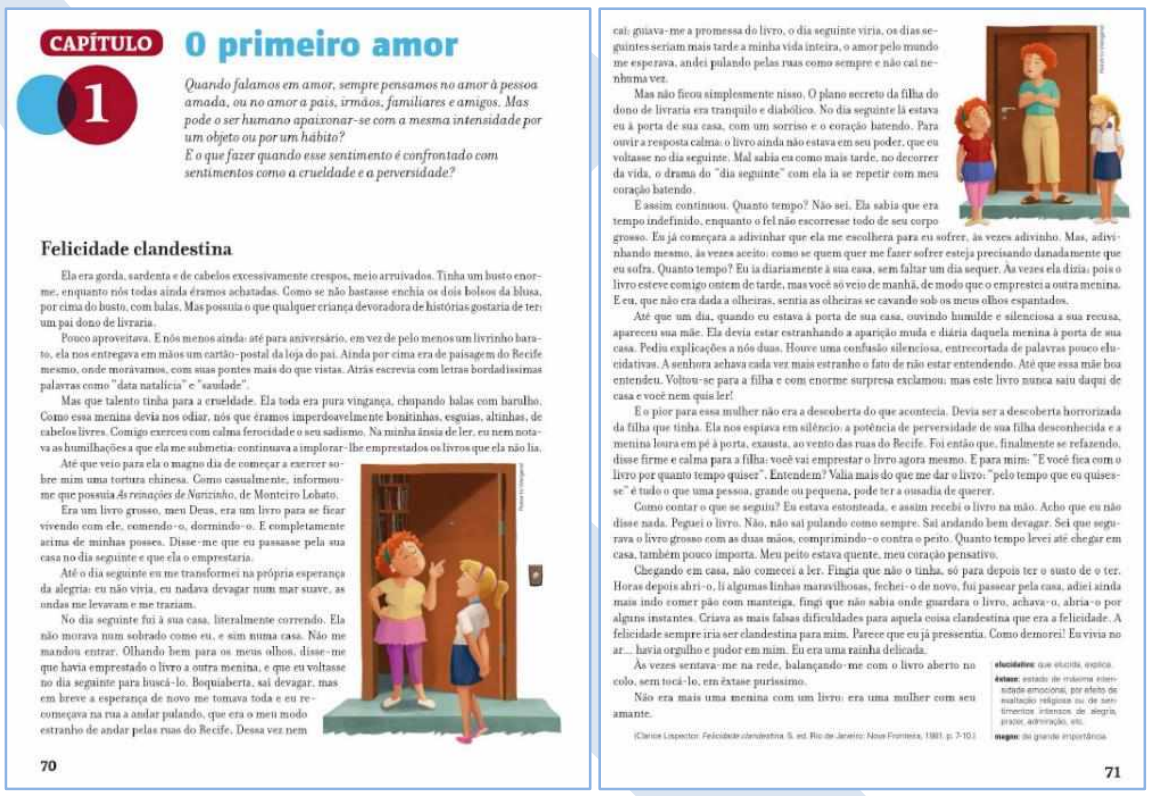

Fonte: Livro didático Português: Linguagens $9^{\circ}$ ano

A Unidade 2, ora analisada, demonstra a clara intenção dos autores em trazer uma visão mais abrangente do sentimento amor, e o fazem para que os alunos possam perceber que existe amor além do que tradicionalmente conhecem, que o amor é diverso, é plural, mas, acima de tudo, é amor. Essa abordagem é claramente conectada com a Pedagogia Freireana e com o Letramento Crítico, pois tem o objetivo de libertar as amarras de um pensamento conservador e reducionista, além de provocar nos alunos uma percepção mais ampla de diversidade, para que possam amar e respeitar aquilo que para eles não é comum. Os capítulos da Unidade 2 se iniciam com a mesma sistemática da Unidade 1, possuindo 
textos de referência, exceto o capítulo 2, que se inicia apresentando apenas imagens, e pede que os alunos as observem com atenção, valorizando a análise de um texto não verbal.

Posteriormente à leitura dos textos, os alunos são incentivados a realizar uma produção textual, sendo-lhes apresentadas algumas modalidades de gênero textual, como o conto. É nesse momento que o aluno pode exteriorizar as discussões estabelecidas com a leitura dos textos, criando nestes uma mentalidade reflexiva e combativa sobre os temas abordados.

Consideramos o livro objeto desta análise uma ótima ferramenta para o ensino da língua portuguesa, pois apresenta os vários aspectos da linguagem de forma contextualizada, adequada às demandas contemporâneas do seu público-alvo, e relaciona de forma natural língua e literatura. No entanto, ressaltamos que, embora importante, o material didático não realiza esse trabalho sozinho. Para que o ensino crítico aconteça, o professor deve exercer o papel de mediador eficiente e capaz de utilizar todas as possibilidades que o livro didático oferece, complementando-o e/ou corrigindo-o quando julgar necessário, conduzindo a produção do conhecimento por parte do aluno de forma crítica e socialmente engajada.

\section{Considerações finais}

Neste artigo, discutimos o conceito de Letramento Crítico, suas origens no pensamento freireano a respeito da educação e suas contribuições para o ensino crítico de língua portuguesa. Consideramos salutar a contextualização dos conteúdos e o debate que leve ao engajamento social e distancie o aluno da alienação.

Tendo nos disposto a refletir acerca das contribuições do Letramento Crítico e da Pedagogia Freireana para o ensino de língua portuguesa a partir da análise do livro didático Português: Linguagens $9^{\circ}$ ano, averiguamos que suas unidades temáticas são construídas a partir de uma abordagem crítica e contemplam gêneros textuais que refletem as práticas de letramento contemporâneas. Além disso, as atividades de leitura e produção textual propostas 
são condizentes com a realidade social do seu público-alvo. Os resultados dessa investigação qualitativa de análise documental demonstraram que o livro didático em questão possui potencialidades de colaboração para a formação de um leitor crítico e socialmente engajado.

Encerramos esse trabalho defendendo os conceitos trazidos por Paulo Freire e pelo Letramento crítico, para que possamos, enquanto educadores, sempre incentivar um modelo crítico de educação, onde os alunos sejam submetidos a práticas pedagógicas emancipadoras, que os tornem capazes de discutir um projeto de sociedade, não sendo apenas ventrículos guiados por aqueles que detêm o poder. Afinal, acreditamos que a revolução vem da educação e, como Freire, enxergamos a educação como o caminho para a emancipação social.

\title{
CRITICAL LITERACY AND PORTUGUESE LANGUAGE TEACHING: THE ANALYSIS OF A TEXTBOOK
}

\begin{abstract}
This article aims to present the results of the analysis of a Portuguese language textbook in light of the theoretical contributions of Critical Literacy studies, derived from the Freirean Pedagogy. The book in question is Português: Linguagens $9^{\circ}$ ano by William Cereja and Thereza Cochar. We were interested in evaluating whether its thematic units were constructed from a critical approach, whether they included textual genres that reflect contemporary literacy practices and whether the proposed reading activities were consistent with the social reality of their target audience. The results of this qualitative research of documental analysis demonstrated that the mentioned textbook has the potential of collaboration for the formation of a critical and socially engaged reader.
\end{abstract}

KEYWORDS: Critical Literacy; Freirean Liberatory Pedagogy; Portuguese Language Critical Teaching.

\section{REFERÊNCIAS}

BAKHTIN, Mikhail (Voloshinov). Marxismo e filosofia da linguagem. 3. ed., São Paulo: Hucitec, 2002.

BALTAR, Marcos; BEZERRA, Charlene. Paulo Freire e os Estudos Críticos do Letramento: O Sulear e a Relação Norte-Sul. Revista Linguas \& Letras, Unioeste, v. 15, n. 28, p. 142-159, jan./jul. 2014.

FREIRE, Paulo. Pedagogia do oprimido. 50. ed. rev. e atual. Rio de Janeiro: Paz e Terra, 1987. 
FREIRE, Paulo. A Importância do Ato de Ler: em três artigos que se completam. 23. ed., São Paulo: Autores Associados: Cortez, 1989.

. Pedagogia da autonomia: saberes necessários à prática educativa. 2. imp., 43. ed., Rio de Janeiro: Paz e Terra, 1996.

. Papel da educação na humanização, 1997. Disponível em: http:/ / acervo.paulofreire.org/xmlui/search?fq=location.coll\%3A6. Acesso em: abr. 2013.

GERALDI, João Wanderley. O texto na sala de aula. Paraná: Assoeste, 1984.

KLEIMAN, Ângela. Preciso "ensinar" o letramento? Não basta ensinar a ler e a escrever? Brasil: Ministério da Educação, 2005.

Os Estudos de Letramento e a Formação do professor de língua Materna. Linguagem em (Dis)curso - LemD, v. 8, n. 3, p. 487-517, set./dez. 2008.

JORDÃO, Clarissa; FOGAÇA, Francisco Carlos. Ensino de Inglês, Letramento Crítico e Cidadania: um triângulo amoroso bem-sucedido. Linguas e Letras: estudos linguísticos, v. 8, n. 14, p. 79-105, jan./jun. 2007.

MONTE MOR, Walkyria Maria. Investigating Critical Literacy at the University in Brazil. Critical literacy: theories and practices, v. 1, n.1, p. 41-51, jul. 2007.

. Convergência e Diversidade no Ensino de Línguas: Expandindo visões sobre a "diferença". Polifonia, v. 21, n. 29, p. 234-253, jan./jul. 2014.

RAJAGOPALAN, Kanavillil. Por uma linguística crítica. Linguagem, Identidade e a Questão Ética. São Paulo: Parábola Editorial, 2003.

ROJO, Roxane. Letramentos múltiplos, escola e inclusão social. São Paulo: Parábola, 2009.

. Letramentos escolares: coletânea de textos nos livros didáticos de Língua Portuguesa. Perspectiva. Florianópolis, v. 28, n. 2, jul/dez. 2010. Disponível em:

< http://educa.fcc.org.br/pdf/rp/v28n02/v28n02a07.pdf>.

Recebido em: 01/11/2019.

Aprovado em: 06/04/2020 